\title{
Rapid detection of human heart-type fatty acid-binding protein in human plasma and blood using a colloidal gold-based lateral flow immunoassay
}

\author{
YANG-GUANG REN $^{1 *}$, MEI-CHEN LIU ${ }^{3 *}$, MENG-ZHEN JI $^{3 *}$, CHEN CHEN $^{3}$, \\ HANG-ZHAN HU ${ }^{3}$, ZI-XUAN WANG ${ }^{1}$, PIN-QIAN YU ${ }^{3}$, JIA-MING SHANG ${ }^{3}$, QIAN-WEN ZHOU ${ }^{3}$, \\ NING-YA TAO ${ }^{3}$, YA-FEI GUO ${ }^{3,4}$, YAN-JIAO LU ${ }^{1}$ and ZHI-ZENG WANG ${ }^{3}$
}

\begin{abstract}
${ }^{1}$ Department of Breast and Thyroid Surgery; ${ }^{2}$ Cardiovascular Surgery, Huaihe Hospital of Henan University;
${ }^{3}$ Joint National Laboratory for Antibody Drug Engineering, Key Laboratory of Cellular and Molecular Immunology of Henan Province, School of Basic Medical Sciences, Henan University, Kaifeng, Henan 475004; ${ }^{4}$ School of Medical Laboratory, Sanquan College of Xinxiang Medical University, Xinxiang, Henan 453003, P.R. China
\end{abstract}

Received June 11, 2020; Accepted February 15, 2021

DOI: $10.3892 / \mathrm{etm} .2021 .10673$

\begin{abstract}
The incidence of acute myocardial infarction (AMI) is currently increasing. Early detection is important for the treatment and prognosis of patients with AMI. Heart-type fatty acid-binding protein (H-FABP) may be used as an early marker of AMI due to its high sensitivity, specificity and prognostic value. Therefore, in the present study, H-FABP was used as a biomarker in a double-antibody sandwich method and colloidal gold-based lateral flow immunoassay to develop a rapid detection kit for H-FABP with a processing time of only $5 \mathrm{~min}$. The sensitivity of the kit in plasma and whole blood was $1 \mathrm{ng} / \mathrm{ml}$ and this method had good specificity, exhibiting no cross-reaction with cardiac troponin I, myoglobin or creatine kinase-Mb. The kits had good shelf life and stability, as they were able to be stored at $40^{\circ} \mathrm{C}$ for 30 days. A total of 12 clinical samples were collected for detection and the coincidence rate with the ELISA method was up to $91.67 \%$. Therefore, the present study provided a simple, rapid and economical early-detection in-home testing kit.
\end{abstract}

\section{Introduction}

At present, the incidence and mortality of cardiovascular disease are increasing worldwide $(1,2)$ and acute myocardial

Correspondence to: Dr Zhi-Zeng Wang, Joint National Laboratory for Antibody Drug Engineering, Key Laboratory of Cellular and Molecular Immunology of Henan Province, School of Basic Medical Sciences, Henan University, North Section of Jinming Road, Kaifeng, Henan 475004, P.R. China

E-mail:wzhzeng@126.com

*Contributed equally

Key words: acute myocardial infarction, heart-type fatty acid-binding protein, colloidal gold, rapid detection, plasma, blood infarction (AMI) is a major cause of death (3-5). In addition, AMI exhibits a trend of rapid growth in young and low-income groups (6-8). According to statistics, it is estimated that one-third of patients with AMI die outside the hospital (5). Therefore, an early diagnosis is important for the treatment and prognosis of patients with AMI $(9,10)$. At present, the diagnostic methods for AMI mainly include electrocardiogram (ECG), coronary imaging and biochemical markers for myocardial injury, but they all require expensive testing equipment and complex operation procedures that are time-consuming and laborious (5,11-13). For patients with non-ST-segment elevation on ECG monitoring, a series of serum tests are required (5). These tests consume a large quantity of materials, resulting in a waste of medical resources and environmental pollution. In addition, certain problems, such as low sensitivity, late appearance and low specificity, exist in the detection of existing biochemical markers (14-16). Therefore, a rapid detection method with fast detection and accurate results with an environmentally friendly, economical and convenient application that may be performed at home for the rapid detection of AMI has become a high priority $(11-13,17)$.

Currently, early clinical markers of myocardial infarction include myoglobin (Myo), creatine kinase-Mb (CK-MB), cardiac troponin T (cTnT) and cardiac troponin I (cTnI) (18). A novel type of myocardial marker, heart-type fatty acid-binding protein (H-FABP), has been introduced for the early diagnosis of AMI (13). Under normal physiological conditions, H-FABP does not appear in plasma or tissue fluids, and it may be detected only in the case of myocardial injury; H-FABP begins to increase 1-3 h after the occurrence of acute coronary syndrome. It peaks after $6-8 \mathrm{~h}$ and returns to normal after 12-24 h. It is one of the earliest markers released into the circulating blood during myocardial injury (15).

Myo has a low molecular weight and appears early, and CK-MB takes a long time $(9-30 \mathrm{~h})$ to reach a peak value $(86 \mu \mathrm{g} / \mathrm{l})$ and has poor sensitivity (19). Although the specificity is high, this marker is mainly used for the diagnosis of myocardial 
infarction with a recurrent attack in a short time period due to its short duration $(13,14)$. The cTnT and cTnI markers have high specificity, particularly the appearance of hs-cTnI, but they are limited by the sensitivity of current rapid detection technology; thus, these markers cannot be detected with home detection methods. In addition, due to the long persistence of cTnT and cTnI in the blood, they are useful in the detection of initial ischaemic events but are not reliable in the detection of a reinfarction $(15,20)$. Therefore, the abovementioned myocardial infarction markers are not ideal for the early diagnosis of AMI.

By contrast, H-FABP is mainly found in cardiomyocytes, with high specificity for AMI; furthermore, H-FABP is rapidly released into the blood (14). Therefore, it is superior to other major myocardial infarction markers and is an ideal early diagnostic marker of AMI. In addition, H-FABP has the potential to assist in other clinical diagnoses, such as detecting AMI recurrence and assessing the size of myocardial infarction, to serve as an independent indicator for predicting the relative risk of cardiac events; it has a good prognostic value, for example regarding the prediction of the long-term mortality of a patient and the probability of reinfarction; it may also be used for monitoring the success of reperfusion after AMI $(14,21,22)$.

Lateral tomography is simple, fast, sensitive and economical, and it is widely used for in-home self-tests and real-time detection (23). The choice of labelled probes is critical to the utility and generalization of the detection method. Due to its good biocompatibility, stability and relatively simple preparation, colloidal gold is the most widely used coloured labelling probe and the most developed domestic in vitro diagnostic marker (24). The use of lateral tomography eliminates the need for precision instrumentation, requires no operator training and may produce results in $10 \mathrm{~min}$ (25).

Therefore, in the present study, a lateral flow immunoassay was developed through the use of H-FABP as a marker and colloidal gold as a labelling probe to produce a rapid detection kit for AMI; this kit is able to provide testing that is fast, effective and easy, and may be performed at home.

\section{Materials and methods}

Preparation of colloidal gold. Colloidal gold nanoparticles (GNPs) were synthesized using a sodium citrate reduction method $(26,27)$. GNPs were prepared by heating with an electric furnace (DK-98-II, Tianjin City TAISITE Instrument Co., Ltd.) and an agitator (RCT B S025, IKA), respectively. The effects of ultrapure water from a Millipak terminal filter and Biopak terminal filter (EMD Millipore) on the properties of colloidal gold were also compared. The quality of colloidal gold was controlled by full wavelength scanning, centrifugation and resuspension, transmission electron microscopy and dynamic light scattering (DLS). The solution was cooled and stored at $4^{\circ} \mathrm{C}$.

Optimization of marker $\mathrm{pH}$ and labelling concentration. In this experiment, a $10 \% \mathrm{NaCl}$ colour reaction was used to determine the optimal $\mathrm{pH}$. Colloidal gold was bound by an anti-H-FABP monoclonal antibody (mAb; cat. no. M020203; Hangzhou Biogenome Biotechnology Co., Ltd.). Colloidal gold consists of a gold core and a wrapped double-ion layer to maintain a suspended state. When a strong ion (such as $10 \% \mathrm{NaCl}$ ) is added, the negative-ion layer on the surface of the gold core is destroyed and the precipitating gold sol that emerges turns the solution blue; however, if a sufficient amount of protein binds to all active sites on the surface of the colloidal gold, an additional protective layer is formed on the surface. Thus, no coagulation occurs when strong ions are added. As the concentration of the protective protein decreases, the colour of the colloidal gold changes from the original rose colour to purple and then to blue-grey. The corresponding $\mathrm{pH}+0.5$ when the colloidal gold first changed colour was determined as the optimum $\mathrm{pH}$ of the label.

Similar to the $\mathrm{pH}$ selection principle, the $\mathrm{pH}$ of the colloidal gold was adjusted to the optimum value and the antibodies at different concentrations were added to observe the colour change. The optimal label amount of the corresponding antibody was increased by $20 \%$ based on when the colloidal gold first changed colour.

Preparation of colloidal gold-labelled $m A b$. According to the conditions determined above, the coating concentration of the test line was optimized. Goat anti-mouse $\operatorname{IgG}(1 \mathrm{mg} / \mathrm{ml}$; cat. no. BA1054; Boster Biological Technology Co., Ltd.) was coated on the control line and the test line was coated with different concentrations of anti-H-FABP mAb 2 (cat. no. M020201; Hangzhou Biogenome Biotechnology Co., Ltd.). The colour development of the test strip was observed and the lowest antibody concentration at which the ideal colour developed was selected as the optimal coating concentration.

For antibody conjugation, the adjusted colloidal gold was added to anti-FABP mAb 1 (cat. no. M020203; Hangzhou Biogenome Biotechnology Co., Ltd.). The mixtures were incubated for 30 min under stirring, after which an aqueous bovine serum albumin (BSA; cat. no. A7906; Sigma-Aldrich; Merck $\mathrm{KGaA}$ ) solution was added to a final concentration of $1 \%(\mathrm{w} / \mathrm{v})$. GNP-labelled anti-FABP $\mathrm{mAb}$ conjugates were separated from unreacted antibodies by centrifugation at $9,600 \times \mathrm{g}$ at $4^{\circ} \mathrm{C}$ for $30 \mathrm{~min}$. After the supernatant was removed, the residue was resuspended in a buffer comprising $0.02 \mathrm{M}$ Tris- $\mathrm{HCl}(\mathrm{pH} 7.6)$, $1.0 \%$ BSA, $5 \%$ sucrose and $0.3 \%$ Tween-20 for storage at $4{ }^{\circ} \mathrm{C}$ for up to one year.

Preparation of the H-FABP test kit. As presented in Fig. 1A, the immunoassay test device comprised four parts: A sample pad, an absorption pad, a nitrocellulose (NC) membrane and a polyvinylchloride (PVC) backing card. In brief, goat anti-mouse IgG and anti-H-FABP mAb 2 were separately applied to the NC membrane in $10 \mathrm{mM}$ PBS ( $\mathrm{pH} 7.4$ ) to be used as the control line and the test line, respectively. The NC membrane was then dried for $4 \mathrm{~h}$ at $37^{\circ} \mathrm{C}$ to fix the antibody and the antigen. The NC membrane was pasted onto the PVC strip with the adsorption pad on the top end, while the colloidal gold-conjugated pad overlapped by the sample pad adhered to the bottom end of the NC membrane. The colloidal gold-conjugated pad was prepared by adding the anti-FABP $\mathrm{mAb} 1$-coated GNPs to a glass fibre $\left(50 \mu \mathrm{l} / \mathrm{cm}^{2}\right)$. The resultant conjugated pad was incubated at $37^{\circ} \mathrm{C}$ for $1.5 \mathrm{~h}$ until fully dried. The glass fibre sample pad was submerged in $10 \mathrm{mM}$ PBS (pH 7.4, 0.05\% Tween-20) and dried at $37^{\circ} \mathrm{C}$ for $1.5 \mathrm{~h}$. Finally, the test device was stored at room temperature (RT) prior to use. 

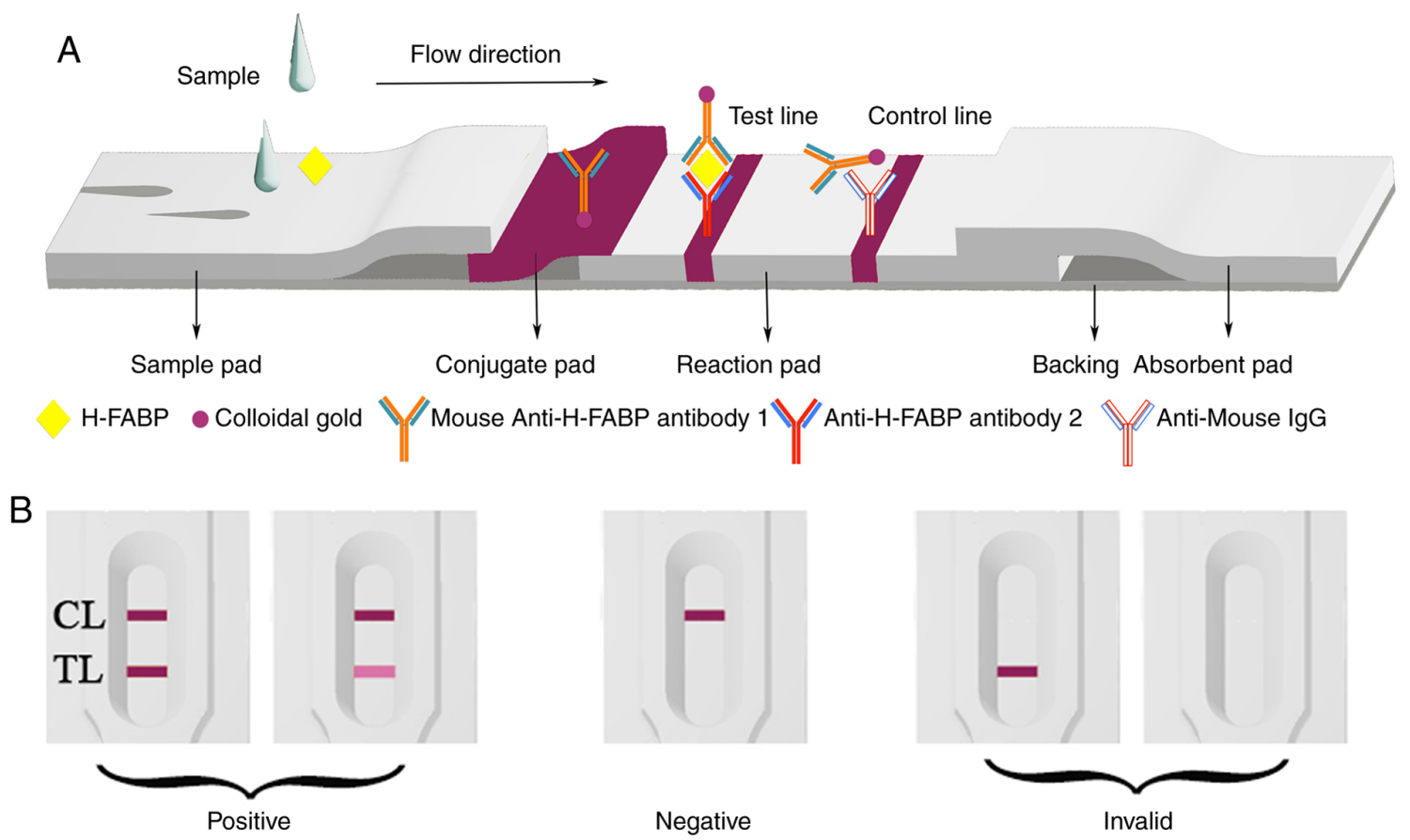

Figure 1. Schematic diagram of the lateral flow immunoassay H-FABP test strip. (A) Preparation and assembly of the immunoassay H-FABP test strip. (B) Evaluation of the possible test strip results. CL, control line; TL, test line; H-FABP, heart-type fatty acid-binding protein.

Determination of the sensitivity, specificity and stability of the H-FABP test kit. Plasma samples were provided by Huaihe Hospital of Henan University (Kaifeng, China) and stored at $-80^{\circ} \mathrm{C}$ for further use. Samples from healthy donors were confirmed to be negative for H-FABP using an ELISA kit (cat. no. HK401; Hycult Biotech Inc.) according to the manufacturer's instructions. A total of 12 samples were collected at Huaihe Hospital from February to April 2019, including 2 normal people (age 72, male; 66, female) and 10 myocardial infarction patients (4 males and 6 females; age range from 69 to 90 , the average age was 75.1 years old). Standard H-FABP was added to the negative samples at concentrations of $0,1,2,5$ or $10 \mathrm{ng} / \mathrm{ml}$, and the samples were mixed completely and stored at RT for $30 \mathrm{~min}$ prior to use. Next, $70-\mu 1$ samples containing H-FABP were tested using the H-FABP test strips in triplicate; If the sample was blood, and dilute with saline. Due to differences in the visual ability between individual observers, particularly for determining low-intensity colour reactions, the strips were analysed with ImageJ v2 software (National Institutes of Health) to evaluate the results.

The cTnI (cat. no. 921807; Beckman Coulter, Inc.), CK-MB (cat. no. 921957; Beckman Coulter, Inc.) and Myo (cat. no. 921849; Beckman Coulter, Inc.) markers $(5 \mu \mathrm{g} / \mathrm{ml})$ were added to different samples and $70 \mu \mathrm{l}$ of each sample was added to the strip sample region for a specificity assay.

A kit was prepared for H-FABP detection with different storage conditions $\left(4^{\circ} \mathrm{C}\right.$, RT and $\left.40^{\circ} \mathrm{C}\right)$ after 30 days for stability verification.

Clinical samples were collected and detected using the H-FABP test kit and the results were revised with the ELISA kit for H-FABP. Information on the patients is presented in Table I. The consistent rate was calculated according to the following formula: Total consistent rate $=($ samples with true positive result + true negatives)/all samples $x 100 \%$. The results were able to be determined with the naked eye within $5 \mathrm{~min}$ (Fig. 1B). The mAb-conjugated GNPs reacted with goat anti-mouse $\operatorname{IgG}$ and were captured in the control zone, while the $\mathrm{mAb}$ combined with GNPs reacted with H-FABP and were able to be captured in the test zone. The positive result was judged by the presence of two rose lines in the reaction area. A negative result was determined by the presence of a single line in the control zone. If no line was present in the reaction area or only one line was present in the test zone, the test was considered invalid.

\section{Results}

Characterization of the colloidal gold. The apparent characteristics of a high-quality colloidal gold solution are a lack of floating material and impurity precipitation in a clear and transparent liquid. In the present experiment, colloidal gold was prepared by reducing $1 \% \mathrm{HAuCl}_{4}$ with $1.5 \%$ sodium citrate and it had a clear and transparent red-rose colour (Fig. 2A-1). After centrifugation, the gold particles were loosely concentrated at the bottom of the Eppendorf (EP) tube; in this state, the clear liquid was colourless and the separation was superior (Fig. 2A-2). After the EP tube was rotated, the precipitate was observed to be in the form of loose sand and was able to be completely suspended, indicating that the colloidal gold had a good resuspension ability (Fig. 2A-3).

Fig. 2B indicates the waveform in a range of $400-700 \mathrm{~nm}$. The wavelength range corresponding to the maximum absorption peak was narrow, suggesting that the particle size of the gold nanoparticles was uniform and the polydispersity index (PDI) of the gold nanoparticles, as measured by DLS, was 0.092 (Fig. 2C). As presented in Fig. 2D, the $\zeta$ potential of colloidal gold was $-35.7 \mathrm{mV}$, indicating that colloidal gold 
Table I. Basic information of donors of clinical samples.

\begin{tabular}{|c|c|c|c|c|c|c|}
\hline $\begin{array}{l}\text { Donor } \\
\text { no. }\end{array}$ & Sex & $\begin{array}{l}\text { Age, } \\
\text { years }\end{array}$ & $\begin{array}{c}\text { Myocardial } \\
\text { infarction } \\
(\text { Yes/No) }\end{array}$ & $\begin{array}{c}\text { Result by } \\
\text { the test strip } \\
(+/-)\end{array}$ & $\begin{array}{c}\text { Result by } \\
\text { ELISA } \\
(\mathrm{ng} / \mathrm{ml})\end{array}$ & $\begin{array}{l}\text { Year-month } \\
\text { of sampling }\end{array}$ \\
\hline 1 & Male & 69 & Yes & + & 1.92 & 2019-03 \\
\hline 2 & Female & 71 & Yes & + & 2.38 & 2019-03 \\
\hline 3 & Male & 81 & Yes & + & 1.78 & 2019-03 \\
\hline 4 & Male & 78 & Yes & + & 3.96 & 2019-03 \\
\hline 5 & Female & 78 & Yes & + & 4.10 & 2019-03 \\
\hline 6 & Female & 79 & Yes & + & 2.42 & 2019-03 \\
\hline 7 & Male & 72 & No & - & 0.26 & 2019-03 \\
\hline 8 & Female & 66 & No & - & 0 & 2019-03 \\
\hline 9 & Female & 79 & Yes & - & 1.21 & 2019-04 \\
\hline 10 & Female & 90 & Yes & + & 6.01 & 2019-03 \\
\hline 11 & Female & 73 & Yes & + & 2.23 & 2019-02 \\
\hline 12 & Male & 83 & Yes & + & 2.75 & 2019-03 \\
\hline
\end{tabular}

All samples were obtained at Huaihe Hospital of Henan University (Kaifeng, China).

may exist stably in a liquid-phase environment. In summary, the custom colloidal gold met the preparation requirements of the kit.

Determination of the optimal labelling $\mathrm{pH}$, concentration and coating concentration. As presented in Fig. 2E, the colour of colloidal gold in the samples no. 1-9, from 0 to $11 \mu \mathrm{l}$ of $\mathrm{K}_{2} \mathrm{CO}_{3}$ volume, changed from grey-blue to rose-red. As the volume of added $\mathrm{K}_{2} \mathrm{CO}_{3}$ increased, the $\mathrm{pH}$ gradually increased and the no. $7\left(\mathrm{~K}_{2} \mathrm{CO}_{3}, 9 \mu \mathrm{l}\right)$ tube did not initially change colour; i.e., it initially turned a rose-red colour. At this point, the $\mathrm{pH}$ of the tube was 6.5 ; thus, the optimal label of the monoclonal antibody was $\mathrm{pH}(6.5+0.5)$, which is 7.0 .

As presented in Fig. 2F, the colour of colloidal gold in samples no. $2-7$, from 0 to $10 \mu \mathrm{g} / \mathrm{ml}$ of antibody concentration, changed from grey-blue to rose-red; no. 1 was the stock solution. As the amount of added protein increased, the no. 4 EP tube did not initially change colour. At first, it was close to rose-red, and at this point, the labelling concentration of the tube was $4 \mu \mathrm{g} / \mathrm{ml}$. Therefore, the optimal labelling concentration of the monoclonal antibody was $(4 \times 120 \%) \mu \mathrm{g} / \mathrm{ml}$, which is $4.8 \mu \mathrm{g} / \mathrm{ml}$.

When H-FABP at 0.5 and $2 \mathrm{mg} / \mathrm{ml}$ was coated on the test strip, the kit detection zone was lighter and the sensitivity was lower. When the test strip was coated with $1 \mathrm{mg} / \mathrm{ml} \mathrm{H-FABP,}$ the quality control strip and the detection strip were superior to those with the other coating concentrations and the sensitivity was $2 \mathrm{ng} / \mathrm{ml}$ (Figs. $2 \mathrm{G}$ and S1). Therefore, the $1 \mathrm{mg} / \mathrm{ml}$ coating was the optimal coating concentration for the H-FABP colloidal gold kit test strip.

Sensitivity of the H-FABP test kit in human plasma and blood. The sensitivity of a kit is a key parameter for the early diagnosis of AMI markers. Therefore, the sensitivity of H-FABP in both plasma and blood matrices was first examined (Fig. 3).
Plasma test. The H-FABP standard was diluted to 10, 5, 2, 1 and $0.01 \mathrm{ng} / \mathrm{ml}$ with no H-FABP plasma and the negative control was free of H-FABP plasma. Subsequently, $70 \mu \mathrm{l}$ of standard solution at different concentrations were added to the sample well to test the sensitivity of the kit in plasma (Figs. 3A and S2). When a negative sample was detected, only the quality control band was coloured and when the sample concentration was $10 \mathrm{ng} / \mathrm{ml}$, the colour of the detection band became most clear to the naked eye and most strongly detected by ImageJ software. With a decrease in sample concentration, the test strip exhibited a positive line with a gradual decrease in the colour intensity of the test lines, and the colour of the test lines was still clearly visible when the sample concentration was $1 \mathrm{ng} / \mathrm{ml}$. However, negative results appeared when the concentration of the sample was $0.01 \mathrm{ng} / \mathrm{ml}$. Therefore, the H-FABP limit of detection for this kit is $1 \mathrm{ng} / \mathrm{ml}$. When the concentration of H-FABP in blood reaches $5 \mathrm{ng} / \mathrm{ml}$, it may be preliminarily judged as myocardial injury $(15,28)$. The sensitivity of this experiment may reach $1 \mathrm{ng} / \mathrm{ml}$, which indicated that the kit is sensitive and has promising clinical application value.

Blood test. The H-FABP standard was diluted with healthy human whole blood to 20,10, 4, 2 and $0.02 \mathrm{ng} / \mathrm{ml}$, and the negative control was healthy human whole blood. To test the sensitivity of the kit with blood, different concentrations of standard solution $(50 \mu \mathrm{l})$ were added to the sample hole of the kit containing a filter membrane with $50 \mu \mathrm{l}$ of normal saline for a blood chromatography test. The actual concentrations of the samples were $10,5,2,1$ and $0.01 \mathrm{ng} / \mathrm{ml}$ healthy human blood. When the concentration of the sample was $0.01 \mathrm{ng} / \mathrm{ml}$ negative control, the detection band did not appear, presenting a negative result. When the concentration of the sample was $1 \mathrm{ng} / \mathrm{ml}$, the positive line was visible with the naked eye; as the concentration of the sample was gradually increased to $10 \mathrm{ng} / \mathrm{ml}$, the colour of the detection belt gradually increased (Fig. 3A), the auxiliary judgment result was shown in Fig. 3D. The repeated trial results were concordant with initial results. 
A
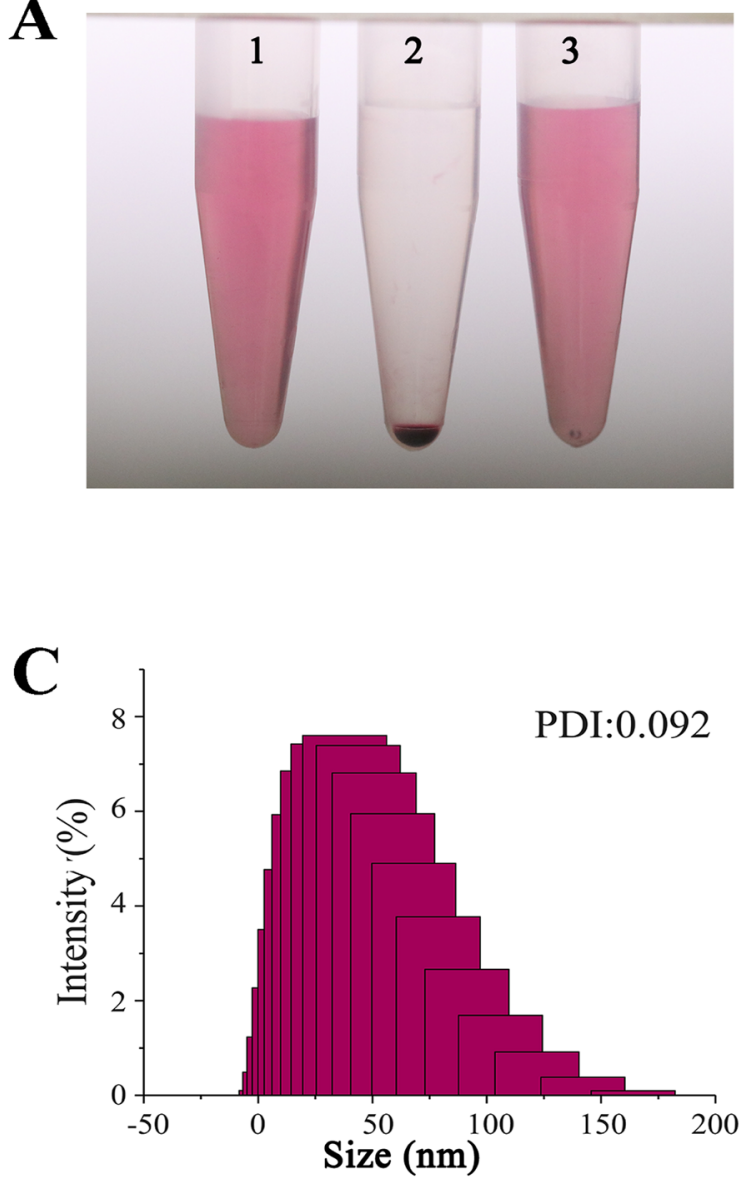

E

Volume of $\mathrm{K}_{2} \mathrm{CO}_{3}(\mu 1)$

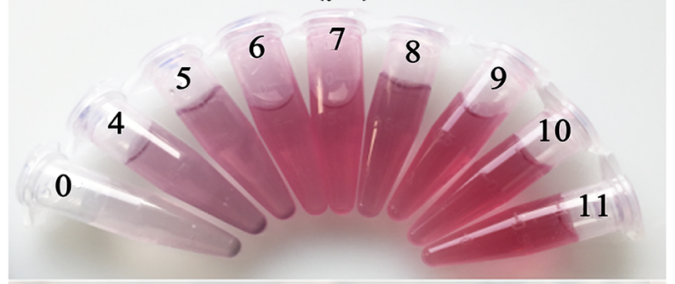

F Concentration of Ab-AuNPs $(\mu \mathrm{g} / \mathrm{ml})$

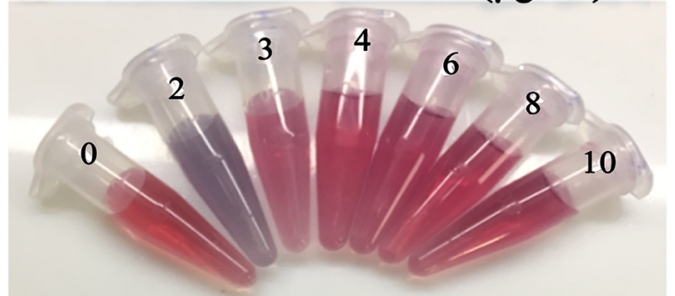

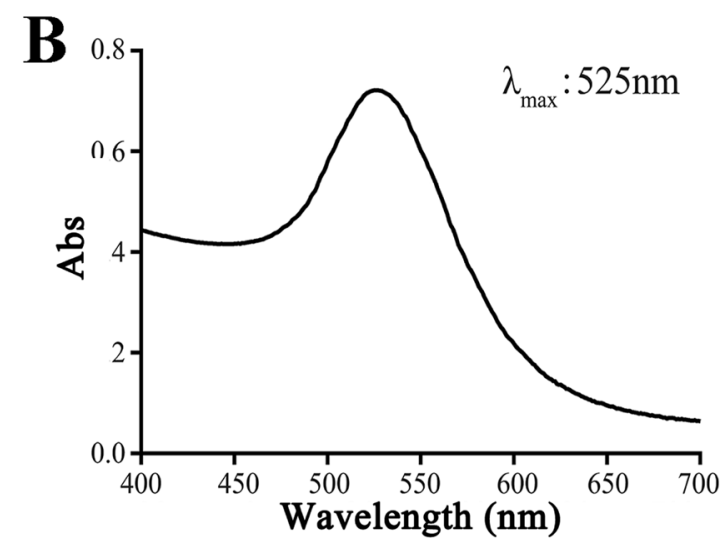

D

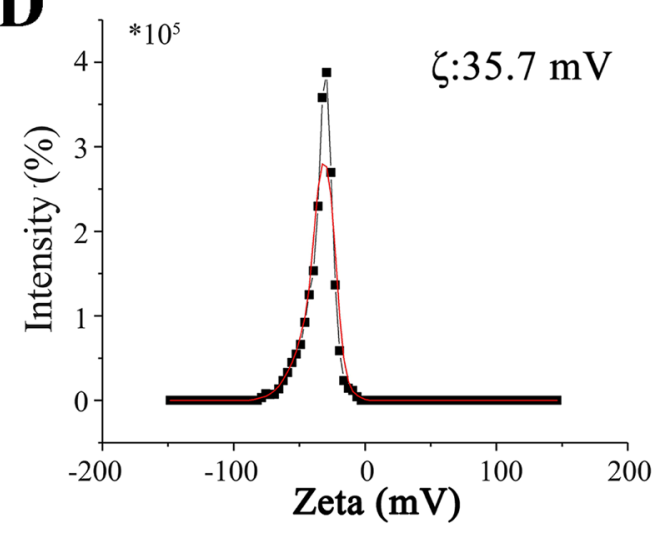

G

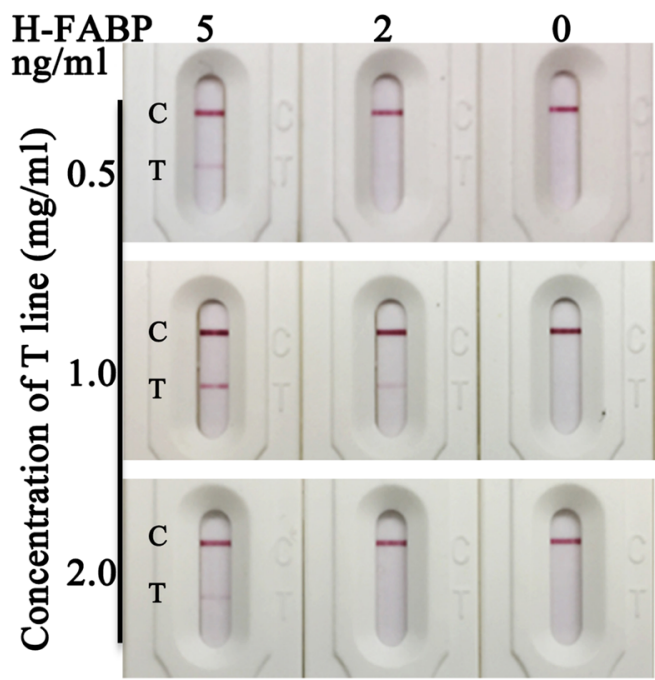

Figure 2. Characterization of colloidal gold and selection of anti-H-FABP antibody labelling conditions. (A) 1, Initial colloidal gold; 2, colloidal gold after centrifugation; and 3, suspended colloidal gold. (B) Full wavelength scanning of colloidal gold. (C) Particle size analysis of colloidal gold. (D) $\zeta$ potential of colloidal gold. (E) NaCl method to optimize the labelling $\mathrm{pH}$ of the anti-H-FABP antibody. (F) Optimization of the labelling concentration of the anti-H-FABP antibody by the $\mathrm{NaCl}$ method. (G) Optimization of the coating concentration of the test line. C, quality control line; T, detection line; $\mathrm{H}-\mathrm{FABP}$, heart-type fatty acid-binding protein; Abs, absorbance; PDI, polydispersity index. 
A
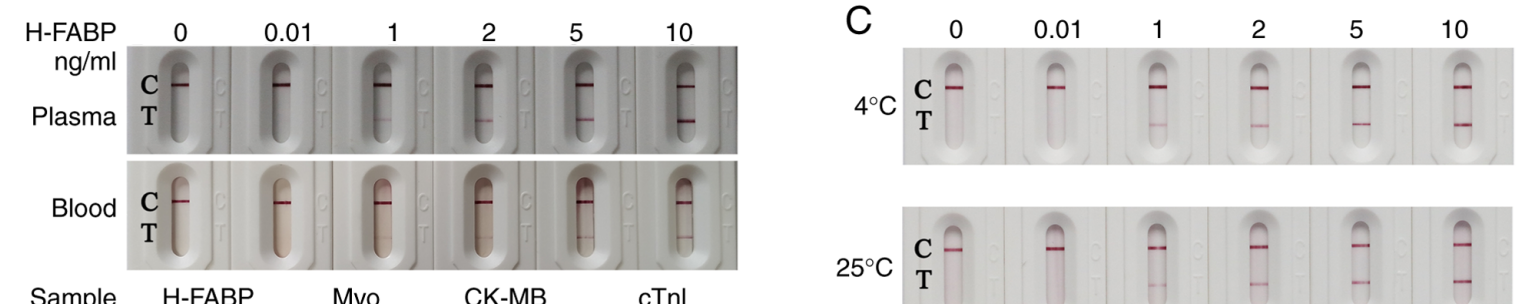

B
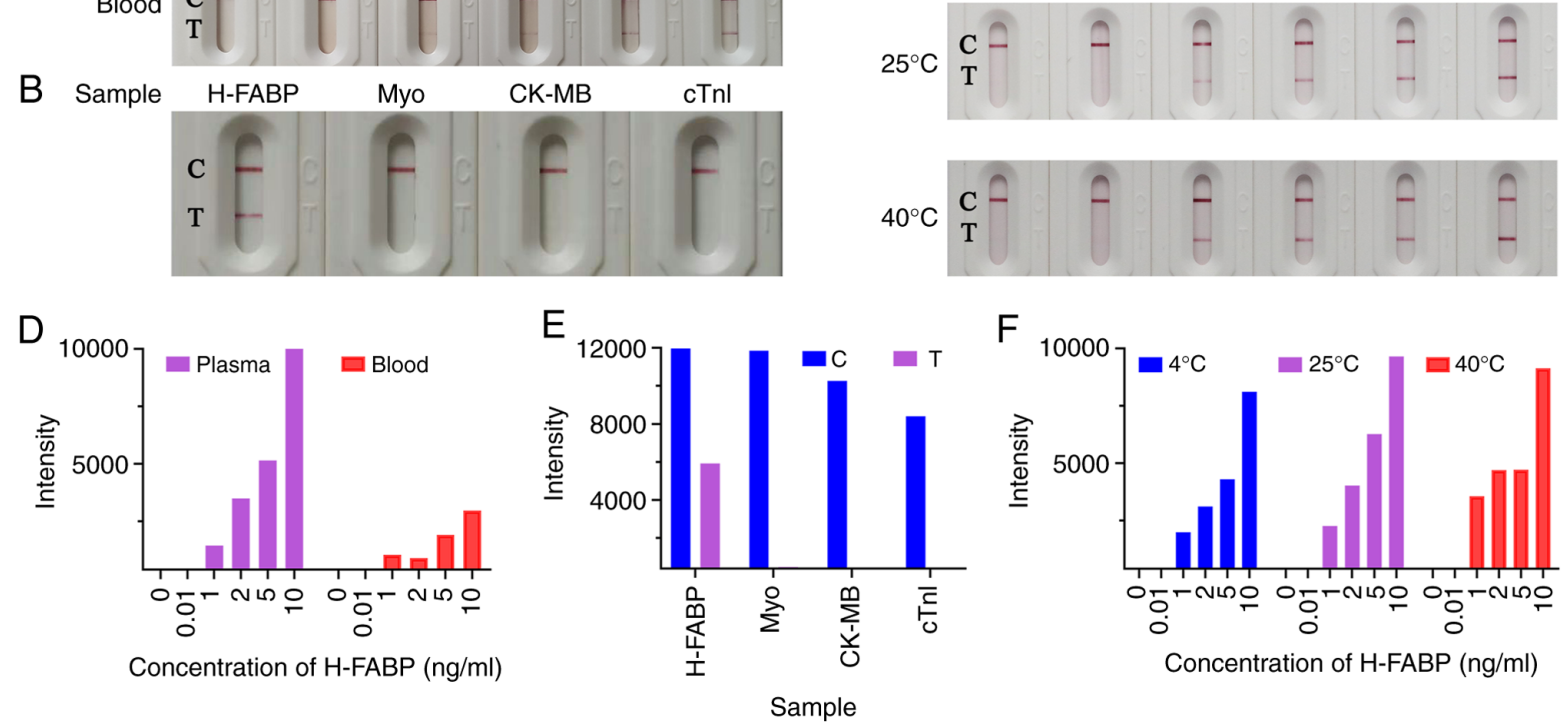

Concentration of H-FABP $(\mathrm{ng} / \mathrm{ml})$

Sample

Figure 3. Sensitivity, specificity and stability assay and assisted interpretation results of the H-FABP rapid test kit. (A) Plasma and whole-blood sensitivity test results. (B) Specificity test results. (C) Stability test results at $4^{\circ} \mathrm{C}$, room temperature and $40^{\circ} \mathrm{C}$. (D) Quantification of plasma and whole-blood sensitivity test results. (E) Quantification of specificity test results. (F) Quantification of stability test results. H-FABP, heart-type fatty acid-binding protein; C, quality control line; T, detection line; cTnI, cardiac troponin I; Myo, myoglobin; CK-MB, creatine kinase-Mb.

Specificity and stability of the H-FABP test kit. In general, specificity is also an important parameter for characterizing the performance of a kit. The specificity of the kit was verified by diluting $5 \mu \mathrm{g} / \mathrm{ml}$ of H-FABP, cTnI, Myo and CK-MB standards without H-FABP plasma. The colour change of the quality control line was not ideal when the test kit detected a large concentration of cTnI. This may be because H-FABP and cTnI have similar epitopes and have certain cross-reactivity. However, as cTnI is also unique to myocardial tissue, its cross-reaction with H-FABP does not affect the diagnosis of AMI (29-31). To make the results more direct, the cTnI samples were redetected at a concentration of $500 \mathrm{ng} / \mathrm{ml}$. As presented in Figs. 3B, E and S3, only H-FABP was used for detection and the difference between the blank and the sample was evident. When the other samples were tested, the quality control band was ideal and the detection band was not coloured; the negative results indicated that the specificity of the kit is excellent.

Good stability has an important role in newly developed kits and clinical applications (24). Kits from the same batch of kits were placed in sealed zipper bags containing desiccant and then stored away from light at $4^{\circ} \mathrm{C}, \mathrm{RT}$ and $40^{\circ} \mathrm{C}$ for 30 days. The kits were then separately used for measurements and the results are presented in Figs. 3C, F and S4. Based on the already mentioned findings, the threshold for evaluating colour changes in the test band was a sample concentration of $1 \mathrm{ng} / \mathrm{ml}$. When the kits were used, the colour changes were still clear. Therefore, the limit of sensitivity was still reach $1 \mathrm{ng} / \mathrm{ml}$, indicating that the kit has high stability.

Clinical sample testing with the H-FABP test kit. Fresh blood from 12 contributors, including 10 patients with myocardial

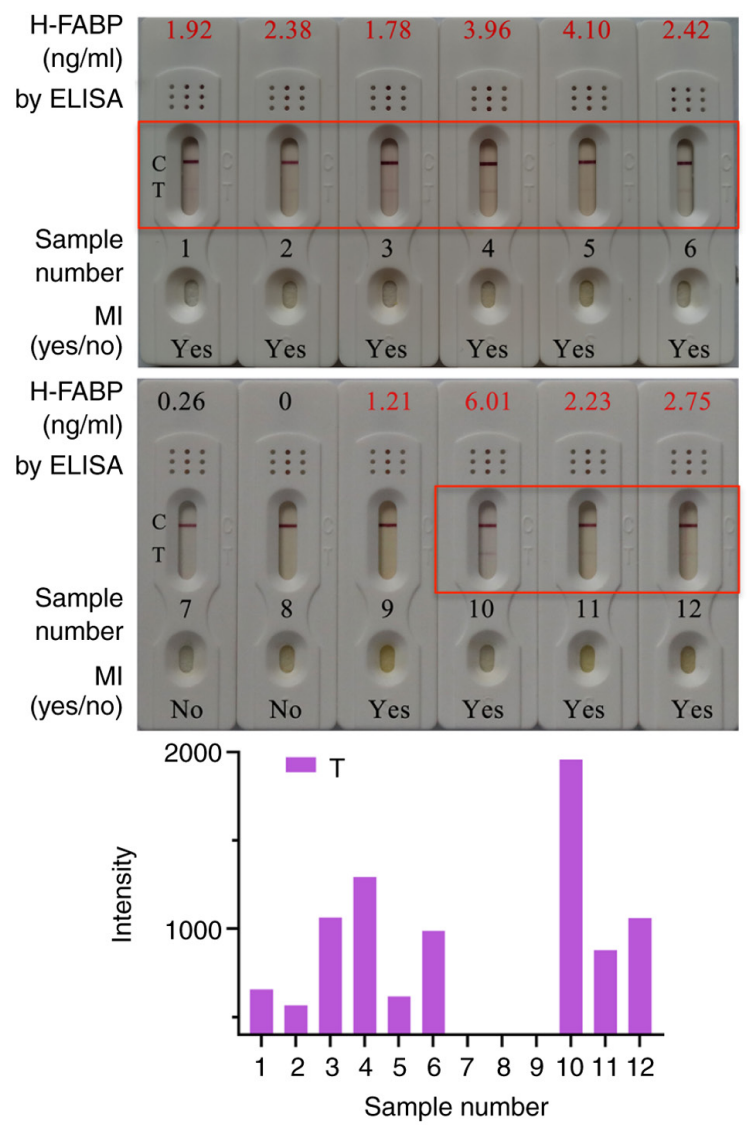

Figure 4. Clinical sample testing and assisted interpretation results by the $\mathrm{H}-\mathrm{FABP}$ rapid test kit based on colloidal gold and the ELISA kit. C, quality control line; T, detection line; MI, myocardial infarction; H-FABP, heart-type fatty acid-binding protein. 
infarction and 2 normal subjects (Table I), was used for clinical sample testing. The plasma was separated and detected by ELISA and the colloidal gold kit. Detection results obtained with the kit for selected clinical samples are presented in Fig. 4. A total of 10 out of the 12 samples had an H-FABP concentration $>1 \mathrm{ng} / \mathrm{ml}$, and the samples of the 2 normal subjects had an H-FABP concentration $<1 \mathrm{ng} / \mathrm{ml}$ according to ELISA detection. For the same cohort, 9 positive results and 3 negative results were obtained with the H-FABP rapid test kit based on colloidal gold. Therefore, a total of $11 \mathrm{H}-\mathrm{FABP}$ kit results were consistent with the ELISA results and the accuracy rate of the statistical kit was $91.67 \%$.

\section{Discussion}

Colloidal gold is one of the most commonly used labelling probes due to its bright colour, easy preparation, good biocompatibility and good optical properties. In this experiment, to obtain stable colloidal gold for the preparation of test strips, the effects of two different heating tools, an electric furnace and an agitator, on the colloidal gold properties after the preparation of colloidal gold were compared. The boiling of the electric furnace was indicated to be more uniform when heated, which is beneficial for the preparation of colloidal gold. The results indicated that the colloidal gold prepared by the Millipak terminal filter was superior to that prepared by the Biopak terminal filter in terms of properties and colour rendering. In summary, aseptic ultrapure water and an electric furnace were selected for the preparation of colloidal gold. The PDI value was $<0.2$, indicating that the distribution of colloidal gold particles was uniform. Furthermore, the absolute value of the $\zeta$ potential of colloidal gold indicated that the colloidal gold had a sufficient repulsive force to maintain a dispersed state; i.e., it may exist stably in a liquid-phase environment.

The purpose of the kit developed in the present study was for use in homes to achieve rapid detection of myocardial infarction; thus, using a simple method is necessary. As blood is thick, to achieve superior chromatographic and colour effects, a diluent was selected to dilute it equally and increase the chromatography speed. First, PBS was selected as the diluent, but in the course of the experiment, false positives were at times obtained. To avoid false positives, saline was used instead of PBS. The osmotic pressure of normal saline is basically the same as the osmotic pressure of a human plasma colloid and no haemolysis occurs when used. In daily life, saline is easy to obtain and more convenient to use. Therefore, saline was chosen as the diluent to achieve more ideal results.

In the detection of clinical samples, the complex plasma composition of the patients may affect the combination of H-FABP and colloidal gold; therefore, the overall colour results of the kit were less evident. Furthermore, the colour of the high-concentration samples was lighter than that of the low-concentration samples; however, it did not affect the assessment of negative and positive results. In addition, the difference in the colour discrimination ability between individual's interpretations of the results compared with the actual results, introduced variability to the results. Finally, to observe the experimental results more intuitively and conveniently, a greyscale analysis by ImageJ software was used to process the colour depth and light colour of the images, and this provided more accurate experimental results. This test kit has the potential to assist in detection before the patient with AMI arrives at the hospital, as the kit provides a rapid detection method.

In conclusion, in the present study, a rapid detection kit for the AMI marker H-FABP was prepared based on colloidal gold. The sensitivity of plasma detection and whole-blood detection was $1 \mathrm{ng} / \mathrm{ml}$, the specificity and stability were excellent, the reproducibility was high, the operation was simple and the detection was rapid; hence, it is suitable for rapid self-examination of patients with suspected myocardial infarction.

\section{Acknowledgements}

Not applicable.

\section{Funding}

This work was supported by the Science and Technology Research Project of Kaifeng Science and Technology Bureau (grant no. 1903097), the Science and Technology Department of Henan Province (grant no. 182102310154) and the Key Scientific Research Project Plan of Colleges and Universities in Henan province (grant no. 19B320003).

\section{Availability of data and materials}

The datasets used and/or analysed during the present study are available from the corresponding author on reasonable request.

\section{Authors' contributions}

ZZW and YGR designed the study; MCL, MZJ, CC, PQY and NYT performed the experiments; and ZXW, JMS, YJL, $\mathrm{HZH}, \mathrm{QWZ}$ and YFG collected and analysed the patient data. ZZW and MZJ confirm the authenticity of all the raw data. All authors read and approved the manuscript.

\section{Ethics approval and consent to participate}

This study was approved by the Biomedical Research Ethics Committee of Henan University (Kaifeng, China; approval no. HUSOM2019-047) and the patients provided written, informed consented to participate.

\section{Patient consent for publication}

Not applicable.

\section{Competing interests}

The authors declare that they have no competing interests.

\section{References}

1. Zhao D, Liu J, Wang M, Zhang X and Zhou M: Epidemiology of cardiovascular disease in China: Current features and implications. Nat Rev Cardiol 16: 203-212, 2019. 
2. Nemet I, Saha PP, Gupta N, Zhu W, Romano KA, Skye SM, Cajka T, Mohan ML, Li L, Wu Y, et al: A cardiovascular disease-linked gut microbial metabolite acts via adrenergic receptors. Cell 180: 862-877.e22, 2020.

3. Roth GA, Johnson C, Abajobir A, Abd-Allah F, Abera SF, Abyu G, Ahmed M, Aksut B, Alam T, Alam K, et al: Global, regional, and national burden of cardiovascular diseases for 10 causes, 1990 to 2015. J Am Coll Cardiol 70: 1-25, 2017.

4. Bajaj A, Sethi A, Rathor P, Suppogu N and Sethi A: Acute complications of myocardial infarction in the current era: Diagnosis and management. J Investig Med 63: 844-855, 2015.

5. Boateng $\mathrm{S}$ and Sanborn T: Acute myocardial infarction. Dis Mon 59: 83-96, 2013.

6. Guo X, Li Z, Vittinghoff E, Sun Y and Pletcher MJ: Trends in rate of acute myocardial infarction among patients aged $<30$ years. Nat Rev Cardiol 15: 119, 2018

7. Arora S, Stouffer GA, Kucharska-Newton AM, Qamar A, Vaduganathan M, Pandey A, Porterfield D, Blankstein R, Rosamond WD, Bhatt DL and Caughey MC: Twenty year trends and sex differences in young adults hospitalized with acute myocardial infarction. Circulation 139: 1047-1056, 2019.

8. Bob-Manuel T, Ifedili I, Reed G, Ibebuogu UN and Khouzam RN: Non-ST elevation acute coronary syndromes: A comprehensive review. Curr Probl Cardiol 42: 266-305, 2017.

9. Friess U and Stark M: Cardiac markers: A clear cause for point-of-care testing. Anal Bioanal Chem 393: 1453-1462, 2009.

10. Morrow DA, Cannon CP, Jesse RL, Newby LK, Ravkilde J, Storrow AB, Wu AH and Christenson RH; National Academy of Clinical Biochemistry: National academy of clinica biochemistry laboratory medicine practice guidelines: Clinical characteristics and utilization of biochemical markers in acute coronary syndromes. Circulation 115: e356-e375, 2007.

11. Leisy PJ, Coeytaux RR, Wagner GS, Chung EH, McBroom AJ, Green CL, Williams JW Jr and Sanders GD: ECG-based signal analysis technologies for evaluating patients with acute coronary syndrome: A systematic review. J Electrocardiol 46: 92-97, 2013.

12. Takagi H, Tanaka R, Nagata K, Ninomiya R, Arakita K, Schuijf JD and Yoshioka K: Diagnostic performance of coronary CT angiography with ultra-high-resolution CT: Comparison with invasive coronary angiography. Eur J Radiol 101: 30-37, 2018.

13. Fung E, Järvelin MR, Doshi RN, Shinbane JS, Carlson SK, Grazette LP, Chang PM, Sangha RS, Huikuri HV and Peters NS: Electrocardiographic patch devices and contemporary wireless cardiac monitoring. Front Physiol 6: 149, 2015.

14. Pyati AK, Devaranavadagi BB, Sajjannar SL, Nikam SV, Shannawaz $M$ and Sudharani: Heart-type fatty acid binding protein: A better cardiac biomarker than CK-MB and myoglobin in the early diagnosis of acute myocardial infarction. J Clin Diagn Res 9: BC08-BC11, 2015.

15. Ye XD, He Y, Wang S, Wong GT, Irwin MG and Xia Z: Heart-type fatty acid binding protein (H-FABP) as a biomarker for acute myocardial injury and long-term post-ischemic prognosis. Acta Pharmacol Sin 39: 1155-1163, 2018.

16. Chen L, Guo X and Yang F: Role of heart-type fatty acid binding protein in early detection of acute myocardial infarction in comparison with cTnI, CK-MB and myoglobin. J Huazhong Univ Sci Technolog Med Sci 24: 449-451, 459, 2004.

17. Neumann JT, Soerensen N, Schwemer T, Ojeda F, Keller T, Renne T, Than M, Parsonage W, Schnabel R, Cullen L, et al: Rapid measurement of a single troponin I combined with negative ECG allow accurate rule-out of NSTEMI in patients with suspected AMI. In: Coronary artery disease, acute coronary syndromes, acute cardiac care. ESC Congress, Rome, Italy, p979, 2016.
18. Wang Y, Yang Y, Chen C, Wang S, Wang H, Jing W and Tao N: One-step digital immunoassay for rapid and sensitive detection of cardiac troponin I. ACS Sens 5: 1126-1131, 2020.

19. Pöyhönen P, Kylmälä M, Vesterinen P, Kivistö S, Holmström M, Lauerma K, Väänänen $H$, Toivonen $L$ and Hänninen $H$ : Peak CK-MB has a strong association with chronic scar size and wall motion abnormalities after revascularized non-transmural myocardial infarction-a prospective CMR study. BMC Cardiovasc Disord 18: 27, 2018.

20. Newby LK, Goldmann BU and Ohman EM: Troponin: An important prognostic marker and risk-stratification tool in non-ST-segment elevation acute coronary syndromes. J Am Coll Cardiol 41 (4 Suppl S): 31S-36S, 2003

21. Reiter M, Twerenbold R, Reichlin T, Mueller M, Hoeller R, Moehring B, Haaf P, Wildi K, Merk S, Bernhard D, et al: Heart-type fatty acid-binding protein in the early diagnosis of acute myocardial infarction. Heart 99: 708-714, 2013.

22. Meng X, Ming M and Wang E: Heart fatty acid binding protein as a marker for postmortem detection of early myocardial damage. Forensic Sci Int 160: 11-16, 2006

23. Henderson WA, Xiang L, Fourie NH, Abey SK, Ferguson EG, Diallo AF, Kenea ND and Kim CH: Simple lateral flow assays for microbial detection in stool. Anal Methods 10: 5358-5363, 2018.

24. Huang X, Aguilar ZP, Xu H, Lai W and Xiong Y: Membrane-based lateral flow immunochromatographic strip with nanoparticles as reporters for detection: A review. Biosens Bioelectron 75: 166-180, 2016.

25. Wang Z, Zheng Z, Hu H, Zhou Q, Li X, Liu W, Li X, Liu Z, Wang Y and Ma Y: A point-of-care selenium nanoparticle-based test for the combined detection of anti-SARS-CoV-2 IgM and IgG in human serum and blood. Lab Chip 20: 4255-4261, 2020.

26. Frens G: Controlled nucleation for the regulation of the particle size in monodisperse gold suspensions. Nat Phys Sci 241: 20-22, 1973.

27. Horisberger $\mathrm{M}$ and Rosset J: Colloidal gold, a useful marker for transmission and scanning electron microscopy. J Histochem Cytochem 25: 295-305, 1977

28. Xu LQ, Yang YM, Tong H and Xu CF: Early diagnostic performance of heart-type fatty acid binding protein in suspected acute myocardial infarction: Evidence from a meta-analysis of contemporary studies. Heart Lung Circ 27: 503-512, 2018.

29. Anaya $\mathrm{P}$ and Moliterno DJ: The evolving role of cardiac troponin in the evaluation of cardiac disorders. Curr Cardiol Rep 15: 420, 2013.

30. Wang Y, Zheng K, Zhan W, Huang L, Liu Y, Li T, Yang Z, Liao Q, Chen $\mathrm{R}$, Zhang $\mathrm{C}$ and Wang $\mathrm{Z}$ : Highly effective stabilization of $\mathrm{Cd}$ and $\mathrm{Cu}$ in two different soils and improvement of soil properties by multiple-modified biochar. Ecotoxicol Environ Saf 207: 111294,2021

31. Fathil MF, Md Arshad MK, Gopinath SC, Hashim U, Adzhri R, Ayub RM, Ruslinda AR, Nuzaihan MNM, Azman AH, Zaki M and Tang TH: Diagnostics on acute myocardial infarction: Cardiac troponin biomarkers. Biosens Bioelectron 70: 209-220, 2015.

This work is licensed under a Creative Commons Attribution-NonCommercial-NoDerivatives 4.0 International (CC BY-NC-ND 4.0) License. 